Open Access

Original Article

\title{
Effects of blood glucose and glycosylated hemoglobin levels on intravenous thrombolysis in patients with acute cerebral infarction and type 2 diabetes mellitus
}

\author{
Zhaoting Zhang ${ }^{1}$, Mingyue Qian², Zhonglin $\mathrm{Ge}^{3}$, \\ Ping Zhou ${ }^{4}$, Jianhua Liu', Jiechun Chen ${ }^{6}$
}

\begin{abstract}
Objective: To investigate the effect of fasting plasma glucose (FPG) and glycosylated hemoglobin (HbAlc.) levels on thrombolytic therapy in patients with acute cerebral infarction and type 2 diabetes mellitus.

Methods: A total of 135 patients with acute cerebral infarction were selected for this study. They were divided into study group ( $\mathrm{n}=70$, with acute cerebral infarction \& type 2 diabetes mellitus) and control group ( $n=65$, with acute cerebral infarction but no type 2 diabetes mellitus). All patients underwent thrombolysis treatment with Alteplase for injection. The patients were evaluated by the national institutes of health stroke scale (NIHSS) score, the modified Rankin scale (MRS) score and the Barthel index score, such indicators in patients as FPG, HbAlc, triglyceride (TG), low density lipoprotein cholesterol (LDL-C), total cholesterol (TC) and high density lipoprotein cholesterol (HDL-C) were determined, the fast blood sugar before thrombolysis and the treatment effect after $24 \mathrm{~h}$ thrombolysis in the observation group were observed and meanwhile the mortality rate in patients after 5 months thrombolysis was analyzed.

Results: Compared with before thrombolysis, the indexes of the two groups were significantly improved after thrombolysis, and the improvements of FPG, HbAlc, TG and LDL-C in the control group were better than those in the study group $(\mathrm{P}<0.05)$. There was no significant difference between the two groups in the levels of TC and HDL-C after thrombolysis $(P>0.05)$. The 24h MBG, SDBG and MAGE in the study group were higher than those in the control group $(\mathrm{P}<0.05)$. In the study group, when the blood glucose was less than $6.0 \mathrm{mmol} / \mathrm{L}$ before thrombolysis, the lowest effective rate after $24 \mathrm{~h}$ thrombolysis was $33.3 \%$, and when the blood glucose was ranging from 7.0 to $9.0 \mathrm{mmol} / \mathrm{L}$, the highest effective rate after $24 \mathrm{~h}$ thrombolysis was $73.9 \%$, and with the gradual increase of blood glucose, the effective rate after $24 \mathrm{~h}$ thrombolysis decreased gradually. Also the effective rate after $24 \mathrm{~h}$ thrombolysis also decreased gradually with the increase of HbAlc value, it reached the highest value of $64.4 \%$ at $\mathrm{HbAlc}<6.0 \mathrm{mmol} / \mathrm{Lad}$ the lowest value of $25 \%$ at HbAlc $>7.0 \mathrm{mmol} / \mathrm{L}$. Compared with the control group, the MHSS score and MRS score were higher and the Barthel index after thrombolysis was lower in the study group with the difference being statistically significant $(P<0.05)$. The five months mortality rate after thrombolytic therapy was $12.9 \%(9 / 70)$ in the study group and $10.8 \%(7 / 65)$ in the control group, with no significant difference between the two groups $(P=0.316)$. The incidence of intracranial hemorrhage after thrombolytic therapy was higher in the study group than in the control group, but the difference was not statistically significant $(P>0.05)$, however there was significant difference between the two groups in revascularization and prognosis $(\mathrm{P}<0.05)$.

Conclusion: The level of HbAlc affected the curative efficacy, the higher the level, the poorer the efficacy and to control the blood glucose within a certain range before thrombolysis was beneficial to enhance the effect of static thrombolysis.
\end{abstract}

KEYWORDS: Acute Cerebral Infarction, Glycosylated Hemoglobin, Intravenous Thrombolysis.

doi: https://doi.org/10.12669/pjms.35.3.8

How to cite this:

Zhang Z, Qian M, Ge Z, Zhou P, Liu J, Chen J. Effects of blood glucose and glycosylated hemoglobin levels on intravenous thrombolysis in patients with acute cerebral infarction and type 2 diabetes mellitus. Pak J Med Sci. 2019;35(3):862-867. doi: https://doi.org/10.12669/pjms.35.3.8

This is an Open Access article distributed under the terms of the Creative Commons Attribution License (http://creativecommons.org/licenses/by/3.0), which permits unrestricted use, distribution, and reproduction in any medium, provided the original work is properly cited.

Pak J Med Sci May - June 2019 Vol. 35 No. $3 \quad$ www.pjms.org.pk 862 


\section{INTRODUCTION}

Diabetes has got increasingly high incidence rate year by year and became a worldwide disease as well as a public health problem. Diabetes mellitus is an independent risk factor of first stroke and also an important factor affecting the prognosis of cerebral infarction. ${ }^{1}$ China is one of the countries with the highest incidence and mortality rate of ischemic stroke in the world. The disease of cerebral infarction has caused great losses and heavy burdens for the family, society and the country. Acute cerebral infarction is one of the most common and serious complications of diabetes mellitus. ${ }^{2}$ Its incidence in diabetic patients is 2.5-3.5 times higher than that in non-diabetic patients. According to statistics ${ }^{3}$, about $20 \%$ of patients with acute cerebral infarction have diabetes. It has worse prognosis in diabetic patients than in those without diabetes history. Intravenous thrombolysis is one of the methods confirmed to be effective in acute cerebral infarction. The current guidebook to ultra-early intravenous thrombolysis for cerebral infarction strict rules on the blood glucose of patients conforming to time windows because the over high blood sugar will increase the risk of intravenous thrombolysis and affect the prognosis. ${ }^{4,5}$ There are few studies about the effect of blood glucose fluctuation on thrombolytic therapy for cerebral infarction.

Our objective was to investigate the effect of fasting plasma glucose (FPG) and glycosylated hemoglobin (HbAlc.) levels on thrombolytic therapy in patients with acute cerebral infarction and type 2 diabetes mellitus.

\section{METHODS}

We selected 135 patients with acute cerebral infarction admitted to our hospital from January 2016 to May 2017 for this study.

\section{Inclusion Criteria:}

1. Patients were aged $20-80$

2. The signs of brain function impairment persisted more than 30 minutes and the National Institutes of Health Stroke Scale (NIHSS) score was 4-24.

3. The disease time was within $4.5 \mathrm{~h}$.

4. Patients were in line with WHO diagnostic criteria for diabetes, 1999.

\section{Exclusion Criteria:}

1. Patients with cerebral hemorrhage or bleeding tendency of other systems.

2. Patients with dysfunction of organs such as heart and liver.

3. Women during pregnancy and lactation.
4. Patients with allergic constitution.

The selected patients were divided into the group consisting of 70 patients with acute cerebral infarction and type 2 diabetes mellitus (study group) and the group consisting of 65 patients with acute cerebral infarction but no type 2 diabetes mellitus (control group). In the study group there were 40 male and 30 female aged 35-74 (64.2 \pm 5.5$)$ years and with a history of diabetes for 2-16 years, including 42 cases with hypertension and 28 with hyperlipidemia. In the control group, there

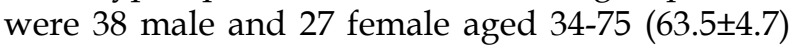
years, including 38 with hypertension and 27 with hyperlipidemia. There was no significant difference between the two groups in patients gender, age and cerebral infarction status $(\mathrm{P}>0.05)$, suggestive of comparability.

All patients were given thrombolysis therapy with Alteplase for Injection (rt-PA) freeze-dry powder (provided by Beijing Aide Pharmaceutical Co., Ltd.)., ten percent of which was diluted at the total dose of $0.9 \mathrm{mg} / \mathrm{kg}$ with physiological saline $(10 \mathrm{ml})$ within three hours of symptoms emerging followed by peripheral intravenous injection, after 1min, the remaining 90\% was diluted with physiological saline $(250 \mathrm{ml})$ followed by continuous injection for $60 \mathrm{~min}$ through infusion pump, the maximum treatment dose being $90 \mathrm{mg}$. At $24 \mathrm{~h}$ after thrombolytic therapy, patients were not given aspirin or clopidogrel and those with diabetes or stress-induced hyperglycemia after cerebral infarction underwent glucose-lowering treatment with insulin, which was forbidden in patients with severe stroke (by clinical diagnosis or imaging diagnosis) and with the basic value of blood glucose under $2.78 \mathrm{mmol} / \mathrm{L}$ or over $22.22 \mathrm{mmol} / \mathrm{L}$.

Observation Index: 1 . The patients were extracted $10 \mathrm{ml}$ venous blood at admission and after $24 \mathrm{~h}$ thrombolysis, which was vetted by clinical laboratory for determinations of such indicators as plasma glucose (PG), glycosylated hemoglobin (HbAlc), triglycerides (TG), total cholesterol (TC), high density lipoprotein cholesterol (HDL-C) and low density lipoprotein the cholesterol (LDL-C).

2. The evaluation of indexes for dynamic blood glucose:

(a) Mean blood glucose (MBG): the normal value was under $6.6 \mathrm{mmol} / \mathrm{L}$;

(b) Standard deviation of blood glucose (SDBG): its assessment deviates from the value of average blood glucose on the whole, reflecting the discrete characteristics of glucose, but unable to distinguish between the main and 
Table-I: Comparison of blood glucose and blood lipid between the 2 groups.

\begin{tabular}{llcccccc}
\hline Group & Time & $\begin{array}{c}\text { FPG } \\
(\mathrm{Mmol} / \mathrm{L})\end{array}$ & $\begin{array}{c}\text { Hbalc } \\
(\%)\end{array}$ & $\begin{array}{c}\text { TC } \\
(\mathrm{Mmol} / \mathrm{L})\end{array}$ & $\begin{array}{c}\text { TG } \\
(\mathrm{Mmol} / \mathrm{L})\end{array}$ & $\begin{array}{c}H D L-C \\
(\mathrm{Mmol} / \mathrm{L})\end{array}$ & $\begin{array}{c}L D L-C \\
(\mathrm{Mmol} / \mathrm{L})\end{array}$ \\
\hline Control Group & Before & $4.6 \pm 0.8$ & $4.6 \pm 0.6$ & $4.2 \pm 0.9$ & $1.8 \pm 0.6$ & $1.1 \pm 0.8$ & $2.5 \pm 0.7$ \\
(N=65) & After & $3.2 \pm 0.4$ & $2.7 \pm 0.3$ & $2.8 \pm 0.7$ & $1.1 \pm 0.5$ & $0.8 \pm 0.4$ & $1.9 \pm 0.5$ \\
Study Group & Before & $7.3 \pm 2.7$ & $7.8 \pm 1.5$ & $4.2 \pm 0.8$ & $2.4 \pm 1.2$ & $1.1 \pm 0.6$ & $3.1 \pm 0.6$ \\
(N=70) & After & $5.6 \pm 1.3$ & $5.4 \pm 1.4$ & $2.7 \pm 0.6$ & $1.9 \pm 0.6$ & $0.9 \pm 0.7$ & $2.2 \pm 0.4$ \\
t/P Control Group & --- & $8.125 / 0.000$ & $11.942 / 0.000$ & $7.118 / 0.000$ & $5.445 / 0.000$ & $4.679 / 0.000$ & $5.081 / 0.000$ \\
t/P Study Group & --- & $7.457 / 0.005$ & $6.322 / 0.000$ & $8.464 / 0.000$ & $4.978 / 0.012$ & $4.026 / 0.005$ & $7.143 / 0.000$ \\
t/P Between Groups & & & & & & & \\
After- Thrombolysis & --- & $9.138 / 0.000$ & $10.379 / 0.000$ & $1.054 / 0.183$ & $7.479 / 0.000$ & $1.632 / 0.074$ & $4.992 / 0.003$ \\
\hline
\end{tabular}

minor fluctuations with its normal value under $1.4 \mathrm{mmol} / \mathrm{L}$;

(c) Mean amplitude of glycemic excursions(MAGE): the glucose fluctuation with the amplitude no more than 1 SDBG was set as effective fluctuation, according to direction of the first effective fluctuation, the average value was obtained as the "gold standard" for reflection of blood glucose fluctuation, the normal value being MAGE <3.9mmol/L.

3. The NIHSS score, MRS score and Barthel index score were assessed. The high NIHSS and MRS scores and low Barthel index score indicate poor recovery effect after thrombolytic therapy.

4. The five months mortality after thrombolytic therapy.

Statistical Methods: SPSS 21 software was used for statistical analysis. Enumeration data were represented by rate (\%) and assessed by $x^{2}$ test, and measurement data were expressed by mean \pm standard deviation, and assessed by $t$ test. $\mathrm{P}<0.05$ suggested there was statistically significant difference.

Ethical Consideration: Tis study was approved from the institutional ethical review board of The Second People`s Hospital of LianyungangLianyungang, Jiangsu, China. All the experiments were conducted as per Helsinki's declaration for human volunteers. All subjects gave informed, signed consent to participate in the study by themselves. Ref. No.2016/053/01.

\section{RESULTS}

Compared with before thrombolysis, the indexes of the 2 groups were significantly improved after thrombolysis, and the improvements of FPG, $\mathrm{HbAlc}$, TG and LDL-C in the control group were better than those in the study group $(\mathrm{P}<0.05)$. There was no significant difference between the 2 groups in the levels of TC and HDL-C after thrombolysis $(\mathrm{P}>0.05)$, as shown in Table-I.
The 24h MBG, SDBG and MAGE in the study group were higher than those in the control group, and the difference was statistically significant $(\mathrm{P}<$ 0.05), as shown in Table-II.

In the study group, when the blood glucose was less than $6.0 \mathrm{mmol} / \mathrm{L}$ before thrombolysis, the lowest effective rate after $24 \mathrm{~h}$ thrombolysis was $33.3 \%$, and when the blood glucose was ranging from 7.0 to $9.0 \mathrm{mmol} / \mathrm{L}$, the highest effective rate after $24 \mathrm{~h}$ thrombolysis was $73.9 \%$, and with the gradual increase of blood glucose, the effective rate after $24 \mathrm{~h}$ thrombolysis decreased gradually. The effective rate after $24 \mathrm{~h}$ thrombolysis also decreased gradually with the increase of HbAlc value, it reached the highest value of $64.4 \%$ at HbAlc $<6.0 \mathrm{mmol} / \mathrm{Lad}$ the lowest value of $25 \%$ at HbAlc $>7.0 \mathrm{mmol} / \mathrm{L}$, as shown in Table-III.

Compared with the control group, the MHSS score and MRS score were higher and the Barthel index after thrombolysis was lower in the study group with the difference being statistically significant $(\mathrm{P}<0.05)$, as shown in Table-IV. The five months mortality rate after thrombolytic therapy was $12.9 \%(9 / 70)$ in the study group and $10.8 \%(7 / 65)$ in the control group, with no significant difference between the two groups $\left(\mathrm{X}^{2}=1.085, \mathrm{P}=0.316\right)$.

The incidence of intracranial hemorrhage after thrombolytic therapy was higher in the study group than in the control group with the difference being not statistically significant $(P>0.05)$, but the revascularization and prognosis of the study group were poorer in the study group than in the control group $(\mathrm{P}<0.05)$, as shown in Table- $\mathrm{V}$.

Table-II: Comparison of dynamic glucose parameters and detection indicators between the 2 groups $(\bar{x}, \mathrm{mmol} / \mathrm{L})$.

\begin{tabular}{lcccc}
\hline Group & Case & 24h MBG & SDBG & MAGE \\
\hline Control Group & 65 & $5.7 \pm 1.6$ & $2.3 \pm 0.6$ & $3.4 \pm 0.8$ \\
Study Group & 70 & $8.5 \pm 2.3$ & $3.1 \pm 0.4$ & $4.5 \pm 0.6$ \\
T --- & 6.584 & 9.301 & 7.902 & \\
P --- & 0.000 & 0.000 & 0.000 & \\
\hline
\end{tabular}


Table-III: The effect of fast blood sugar and HbAlc before thrombolysis on the efficacy at $24 \mathrm{~h}$ after thrombolytic therapy in the study group.

\begin{tabular}{|c|c|c|c|c|c|c|c|}
\hline Index & & Case & Age (Years) & Disease Time $(h)$ & Effective (Case) & Invalid (Case) & Effective Rate (\%) \\
\hline \multirow{5}{*}{$\begin{array}{l}\text { BG before } \\
\text { thrombolysis } \\
(\mathrm{mmol} / \mathrm{L})\end{array}$} & $<6.0$ & 12 & $65.4 \pm 6.2$ & $2.8 \pm 1.2$ & 4 & 8 & 33.3 \\
\hline & $6.0-7.0$ & 20 & $65.1 \pm 5.3$ & $2.8 \pm 0.7$ & 11 & 9 & 55.0 \\
\hline & $7.0-9.0$ & 23 & $64.2 \pm 6.1$ & $3.1 \pm 1.3$ & 17 & 6 & 73.9 \\
\hline & $9.0-11$ & 5 & $65.5 \pm 7.4$ & $3.5 \pm 0.8$ & 3 & 2 & 66.7 \\
\hline & $>11.0$ & 10 & $66.1 \pm 5.5$ & $2.8 \pm 1.1$ & 5 & 5 & 50.0 \\
\hline \multirow{4}{*}{$\begin{array}{l}\text { HbAlc before } \\
\text { thrombolysis } \\
(\mathrm{mmol} / \mathrm{L})\end{array}$} & $>6.0$ & 45 & $65.1 \pm 5.4$ & $2.8 \pm 1.1$ & 29 & 16 & 64.4 \\
\hline & $6.0-6.5$ & 12 & $64.6 \pm 5.3$ & $2.7 \pm 1.5$ & 6 & 6 & 50.0 \\
\hline & $6.5-7.0$ & 5 & $65.4 \pm 4.7$ & $3.5 \pm 1.2$ & 2 & 3 & 40.0 \\
\hline & $>7.0$ & 8 & $65.9 \pm 4.8$ & $3.2 \pm 1.4$ & 2 & 6 & 25.0 \\
\hline
\end{tabular}

Table-IV: Comparison of NIHSS, MRS and Barthel index scores between the 2 groups before and after treatment.

\begin{tabular}{|c|c|c|c|c|c|c|c|}
\hline \multirow[t]{2}{*}{ Group } & \multirow[t]{2}{*}{ Case } & \multicolumn{2}{|c|}{ NIHSS Score } & \multicolumn{2}{|c|}{ MRS Score } & \multicolumn{2}{|c|}{ Barthel Index } \\
\hline & & Before & After & Before & After & Before & After \\
\hline Control & 65 & $17.32 \pm 5.72$ & $9.15 \pm 4.33$ & $5.78 \pm 0.71$ & $1.76 \pm 0.45$ & $27.13 \pm 7.06$ & $73.58 \pm 9.75$ \\
\hline Study Group & 70 & $17.28 \pm 5.69$ & $13.24 \pm 4.36$ & $5.76 \pm 0.65$ & $3.13 \pm 0.35$ & $27.15 \pm 7.12$ & $50.34 \pm 6.28$ \\
\hline$t / x^{2}$ & --- & 0.367 & 5.009 & 0.941 & 7.615 & 0.207 & 8.046 \\
\hline $\mathrm{P}$ & --- & 0.225 & 0.016 & 0.378 & 0.014 & 0.318 & 0.011 \\
\hline
\end{tabular}

\section{DISCUSSION}

Existing clinical and epidemiological studies have shown that ${ }^{6-7}$ diabetes mellitus is an independent risk factor for ischemic stroke. The relevant mechanism is described as follow ${ }^{8-9}$ one description is the fact that the vascular endothelial cells of diabetic patients are prone to functional and structural damage; and the other is that high glucose condition gives rise to disorder of lipid metabolism, the above reasons will increase the probability of intravascular thrombosis and the incidence of cerebral infarction. Rt- PA thrombolytic therapy is the most effective treatment for acute cerebral infarction within the time window $(<4.5 \mathrm{~h})$. It effectively rescues the nerve cells in the cerebral ischemic penumbra with rapid restoration of nerve function by dredging occluded blood vessels and recovering blood supply in cerebral infarct areas. At present, it has been recommended in the guidelines for cerebral infarction treatment in many countries and in recent years has been widely applied in domestic comprehensive hospitals. Today many clinicians still have doubts on the intravenous thrombolytic therapy for patients with type 2 diabetes and cerebral infarction, and according to the current guidelines for the diagnosis and treatment of acute cerebral stroke, diabetes is not the contraindication of rt -PA intravenous thrombolysis, but there is also clean requirement proposed on the patient's blood sugar. A research has revealed that ${ }^{10}$ persistent hyperglycemia may indicate poor prognosis in patients after thrombolysis, but there is no definite evidence that proves clear relationship between diabetes and rt-PA thrombolysis induced poor prognosis.

The results of this study showed that the levels of FPG, $\mathrm{HbAlc}$, TG and LDL-C in the study group were higher than those in the control group before and after treatment. Blood sugar fluctuation may also be one of the reasons in addition to atherosclerosis of the arteries caused by long-term hyperglycemia. The researchers have found that, ${ }^{11-12}$ whether in patients with type 2 diabetes or in healthy people, the glucose with excessive fluctuations greatly damages blood vessel endothelium. And the study found that the dynamic blood glucose parameters of 24h MBG, SDBG and MAGE were higher in patients with acute cerebral infarction and type 2 diabetes than in non-type 2 diabetes patients with

Table-V: Comparison of intracranial hemorrhage and prognosis between the two groups [n (\%)].

\begin{tabular}{lcccc}
\hline Group & Case & Intracranial Hemorrhage & Good Revascularization & Poor Prognosis \\
\hline Control Group & 65 & $3(4.6)$ & $46(70.8)$ & $36(55.4)$ \\
Study Group & 70 & $4(5.7)$ & $25(35.7)$ & $25(35.7)$ \\
$\mathrm{x}^{2}$ & --- & 1.015 & 9.842 & 6.337 \\
P & --- & 0.352 & 0.001 & 0.008 \\
\hline
\end{tabular}


acute cerebral infarction. Because the patients in the study group had moderately high glucose and big fluctuation, they also had relatively high risks and more serious condition.

The related research has found that ${ }^{13}$ overhigh concentration of blood glucose can lead to disorders of glucose metabolism and vascular endothelial cell dysfunction, in which there will be glycosylation of platelet membrane, leading to platelet activation and making it more susceptible to induced aggregation with the production of superoxide ions and increased synthesis of thromboxane compounds, nevertheless, the synthesis of vasodilatation factors like nitric oxide or prostacyclin is correspondingly reduced, more likely to cause thrombosis. The extremely low level of blood sugar can trigger inflammation responses and inflammatory factors activate complement followed by a large increase of lipid deposited in vascular wall, which induces atherosclerosis and increases the risk of ACI by infiltration and aggregation of vascular endothelial cells. The results of this study showed that the effective rate after $24 \mathrm{~h}$ thrombolysis was highest when the blood glucose was ranging from 7.0 to $9.0 \mathrm{mmol} / \mathrm{L}$ and before treatment the efficacy of thrombolysis was moderately poorer when the glucose was too high or too low, and when the blood glucose was less than $6.0 \mathrm{mmol} / \mathrm{L}$ before thrombolysis, the effective rate after $24 \mathrm{~h}$ thrombolysis was lowest, only $33.3 \%$. These suggest that different concentrations of pre thrombolytic blood glucose have influences on the efficacy of rt-PA intravenous thrombolysis. Brain is one of human organs with strongest metabolism. Blood sugar is the main source of energy for brain cells, whose capacity of sugar reservation is limited, so when the blood sugar is reduced, the energy needed by brain cells is not sufficiently supplied. In the meantime, the nature of cerebral infarction is attributed to the sudden decrease or cessation of local blood flow of supply artery in brain tissues, leading to cerebral ischemia and hypoxia followed by the resulting brain tissue necrosis and softening. Therefore, the reason for the condition that the effective rate at $24 \mathrm{~h}$ after thrombolysis is lowest when the blood glucose before thrombolysis is under $6.0 \mathrm{mmol} / \mathrm{L}$ may be due to the insufficient supply of energy needed by the brain, which, resulting from low blood glucose fails to realize energy supply during rt-PA thrombolysis and eventually causes poor effect.

The results also showed that the efficiency rate after $24 \mathrm{~h}$ thrombolysis decreased gradually with the increase of $\mathrm{HbA} 1 \mathrm{c}$ value, reaching the highest value at $\mathrm{HbAlc}<6.0 \mathrm{mmol} / \mathrm{L}$ and the lowest at $\mathrm{HbA} 1 \mathrm{c}$ $>7.0 \mathrm{mmol} / \mathrm{L}$. $\mathrm{HbA} 1 \mathrm{c}$ is a product of irreversible binding of hemoglobin in red blood cells with blood glucose. It is directly proportional to blood glucose concentration and can reflect the blood glucose control which is not affected by temporary fluctuation of the concentration. It has been proposed in a number of clinical studies that ${ }^{14-15}$ when the HbA1c level increases, more hemoglobin turns to $\mathrm{HbA1}$, leading to reduction of hemoglobin and lower efficiency of oxygen transport. So, the increase of $\mathrm{HbA1c}$ leads to insufficient energy supply to the brain, leading to the failure of enough energy supply during rt-PA thrombolysis and poor treatment effect.

This study may be a reply to the suggestions of Shihab et al (2015) who documented that controlled trials are needed to determine whether acute correction of hyperglycemia can improve outcomes after thrombolysis. ${ }^{16}$

The results also showed that there was no significant difference between the 2 groups in the scores of various indexes before thrombolysis, but after thrombolysis, the scores of NIHSS and MRS were higher and the Barthel index was lower in the study group compared with the control group. It can be concluded that after thrombolytic therapy the patients without type 2 diabetes mellitus have better recovery than those with, consistent with the conclusion of previous studies. Moreover, those accompanied by type 2 diabetes have higher risk of cerebral hemorrhage with poorer recanalization and prognosis by contrast.

Limitations of this Study: However the main drawback of intravenous thrombolysis is symptomatic intracerebral hemorrhage which is the limitation of this study as there was no study to determine the predictive value of parameters of glycosylated hemoglobin.

To sum up, in the course of intravenous thrombolytic therapy for patients with acute cerebral infarction and type 2 diabetes, the level of HbAlc affected the curative efficacy in patients, the higher the level, the poorer the efficacy, and to control the blood glucose within a certain range (7.0-9.0 $\mathrm{mmol} / \mathrm{L})$ before thrombolysis was beneficial to enhance the effect of static thrombolysis.

Declaration of interest: All authors reach an agreement and declare to have no competing interests. 


\section{REFERENCES}

1. Jin WA, Zai-li LI, Peng LI, Fei YA, SHANG SH, Pei LI, et al. The screening of vascular risk factors for cognitive dysfunction in population with high risk of stroke. Chin J Cont Neur Neurosurgery. 2017;17(2):138-142. doi: 10.1161/ HYP.0000000000000053.

2. Jakobsson S, Bergstrom L, Bjorklund F, Jernberg $T$, Soderstrom L, Mooe T. Risk of ischemic stroke after an acute myocardial infarction in patients with diabetes mellitus. Cir Cardio Qual Outcom. 2014;7(1):95-101. doi: 10.1161/ CIRCOUTCOMES.113.000311.

3. Huang YH, Xia ZX, Wei W, Gao GR, Gong JJ, Li Y, et al. The impact of leucoaraiosis on neurological function recovery in elderly patients with acute cerebral infarction: Clinical study involving 279 Chinese patients. J Int Med Res. 2014;42(3):1223-1227. doi: 10.1177/0300060513507386.

4. Wen T, Rao P, Zhang H. Comparative study of treatment for acute cerebral infarction with intraarterial and intravenous thrombolysis. Chin J Neu Dis Res. 2007;7903(2):43-47. doi: 10.1159/000338389.

5. Kretzer L, Graßel D, Bokemeyer MA, Gunther A, Witte OW, Axer $\mathrm{H}$, et al. Effect of Intravenous Thrombolysis on the Time Course of the Apparent Diffusion Coefficient in Acute Middle Cerebral Artery Infarction. J Neuroimag off J Amer Soc Neuroimag. 2015;25(6):978-982. doi: 10.1111/jon.12240.

6. Guerrero-Romero F, Rodriguez-Moran M. Proteinuria is an independent risk factor for ischemic stroke in noninsulin-dependent diabetes mellitus. Stroke; J Cereb Cir. 1999;30(9):1787-1791.

7. Mondol G, Rahman KM, Uddin MJ, Bhattacharjee M, Dey SK, Israil A, et al. Proteinuria is an independent risk factor for ischemic stroke among diabetic patients. Mym Med J. 2012;21(3):439-444

8. Malyszko J, Malyszko JS, Hryszko T, Mysliwiec M. Thrombin activatable fibrinolysis inhibitor (TAFI) and markers of endothelial cell injury in dialyzed patients with diabetic nephropathy. Throm Haemostas. 2004;91(3):480-486.

9. Wang F, Liu ZY. Correlation between vascular endothelial cell injury, platelet activation and functional status in type 2 diabetes. J F Mil Med Uni. 2006;27(7):637-638.

10. Yong $\mathrm{M}$, Kaste $\mathrm{M}$. Dynamic of hyperglycemia as a predictor of stroke outcome in the ECASS-II trial. Stroke. 2008;39(10):2749-2755.

11. Torimoto K, Okada Y, Mori H, Tanaka Y. Relationship between fluctuations in glucose levels measured by continuous glucose monitoring and vascular endothelial dysfunction in type 2 diabetes mellitus. Cardiovas Dia. 2013;12(1):1.
12. Azuma K, Kawamori R, Toyofuku Y, Kitahara Y, Sato F, Shimizu T, et al. Repetitive Fluctuations in Blood Glucose Enhance Monocyte Adhesion to the Endothelium of Rat Thoracic Aorta. Art Thr Vas Bio. 2006;26(10):2275-2280.

13. Zhang XG, Zhang YQ, Zhao DK, Wu JX, Zhao J, Jiao XM, et al. Relationship between blood glucose fluctuation and macrovascular endothelial dysfunction in type 2 diabetic patients with coronary heart disease. Eur Rev Med Pharm Sci. 2014;18(23):3593-3600.

14. Engoren M, Schwann TA, Habib RH. Response to: Elevated hemoglobin $\mathrm{A} 1 \mathrm{c}$ is associated with readmission but not complications. Asian Card Tho Ann. 2014;22(7):886.

15. Mousavi F, Jahed A, Rajab A, Sokhantabar N, Kamran A, Kashi G. Survey of Air Pollution Effect on Variation of Glycosylated Hemoglobin A1C (HbA1C) level in Diabetic Patients in Tehran. Iran J Heal Env. 2013;6(1):123-132.

16. Shihab M, Margueritte C, Deepak LB, Eric ES, Gray E, Gregg $\mathrm{CF}$, et al. Association of Acute and Chronic Hyperglycemia With Acute Ischemic Stroke Outcomes Post-Thrombolysis: Findings From Get With The Guidelines-Stroke. J Am Heart Assoc. 2015;4. doi: 10.1161/JAHA.115.002193

\section{Authors' Contributions:}

ZZ, MQ: Designed the study, analyzed data and revised the manuscript.

ZG: Selection of patients, randomization and prepared the manuscript.

PZ, LL: Revised the manuscript, participated on data analysis.

JC: Responsible for collecting data and postoperative clinical assessment and revised the manuscript. All authors have approved the final version to be published.

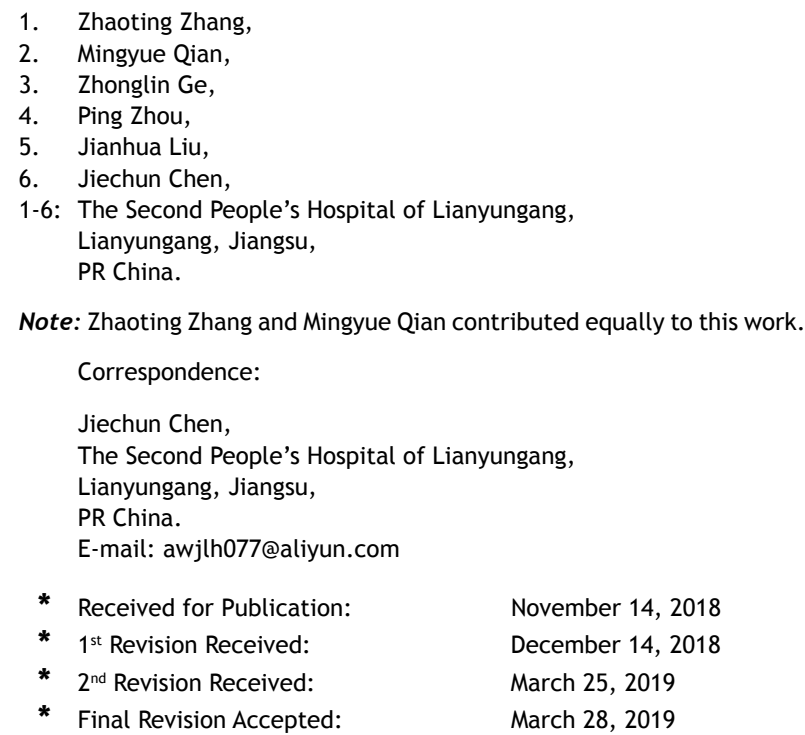

